\title{
Assessing global patterns in mammalian carnivore occupancy and richness by integrating local camera trap surveys
}

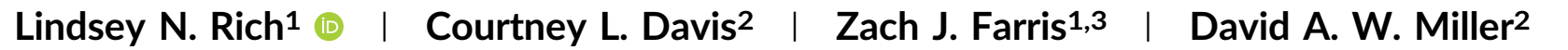 \\ Jody M. Tucker4 | Sandra Hamel5 | Mohammad S. Farhadinia6,7 | \\ Robin Steenweg8 | Mario S. Di Bitetti9,10,11 | Kanchan Thapa1,12 | \\ Mamadou D. Kane ${ }^{13}$ | S. Sunarto14 | Nathaniel P. Robinson ${ }^{15}$ | \\ Agustín Paviolo9,10 | Paula Cruz 9 ,10 | Quinton Martins ${ }^{16,17}$ | Navid Gholikhani6 | \\ Ateih Taktehrani6 | Jesse Whittington ${ }^{18}$ | Febri A. Widodo ${ }^{14}$ | Nigel G. Yoccoz | \\ Claudia Wultsch ${ }^{1,19,20}$ | Bart J. Harmsen ${ }^{19,21}$ | Marcella J. Kelly ${ }^{1}$

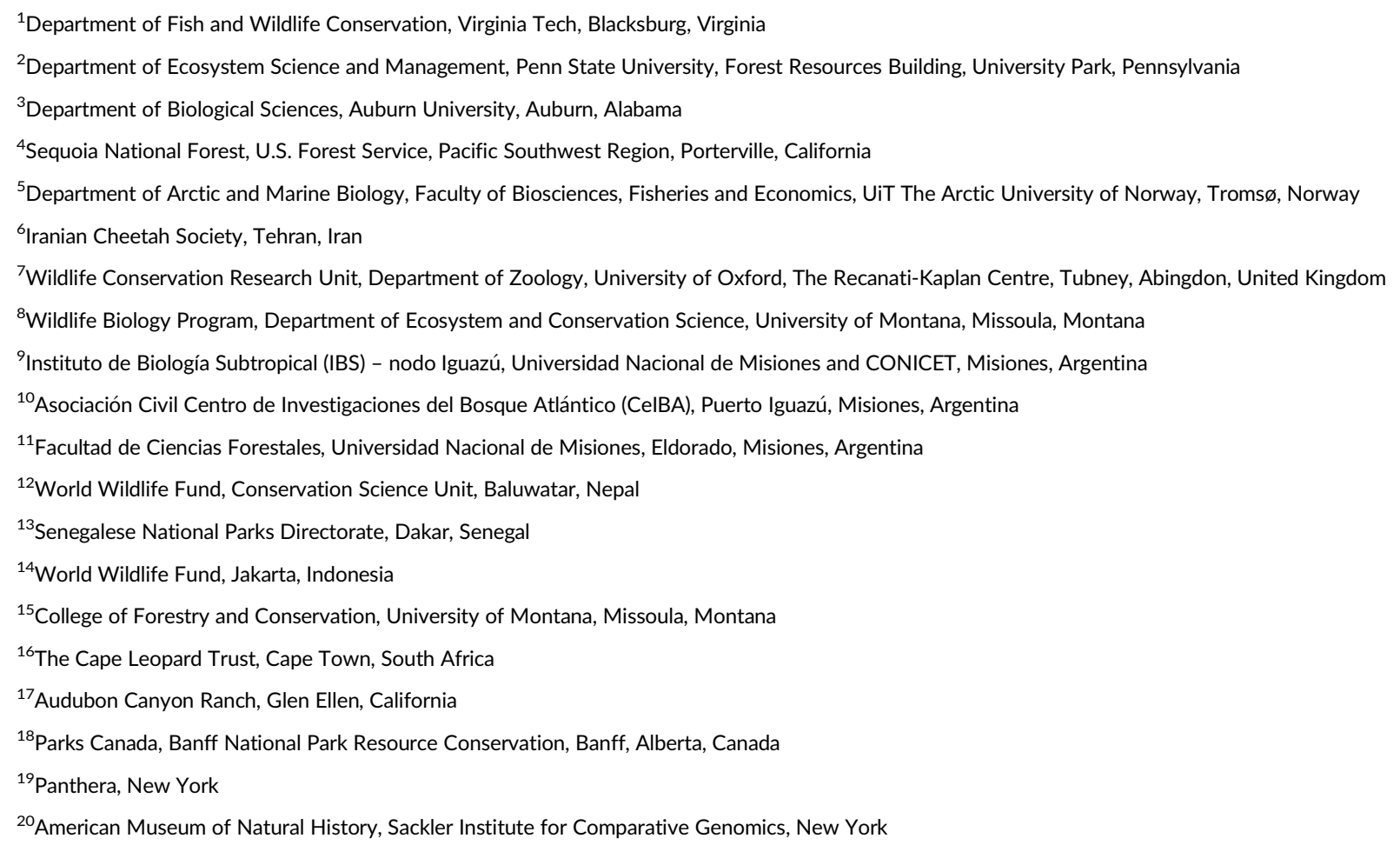

\section{Correspondence}

Lindsey N. Rich, Department of Fish and Wildlife Conservation, Virginia Tech, Blacksburg, VA 24060, U.S.A.

Email: lindseyrich83@gmail.com

Editor: Thomas Gillespie

Funding Information

National Science Foundation for funding

\begin{abstract}
Aim: Biodiversity loss is a major driver of ecosystem change, yet the ecological data required to detect and mitigate losses are often lacking. Recently, camera trap surveys have been suggested as a method for sampling local wildlife communities, because these observations can be collated into a global monitoring network. To demonstrate the potential of camera traps for global
\end{abstract}


part of this project (Long Term Research In Environmental Biology Grant 1556248) monitoring, we assembled data from multiple local camera trap surveys to evaluate the interchange between fine- and broad-scale processes impacting mammalian carnivore communities.

Location: Argentina, Belize, Botswana, Canada, Indonesia, Iran, Madagascar, Nepal, Norway, Senegal, South Africa, and the U.S.A.

Methods: We gathered camera trap data, totalling $>100,000$ trap nights, from across five continents. To analyse local and species-specific responses to anthropogenic and environmental variables, we fitted multispecies occurrence models to each study area. To analyse global-level responses, we then fitted a multispecies, multi-area occurrence model.

Results: We recorded 4,805 detections of 96 mammalian carnivore species photographed across 1,714 camera stations located in 12 countries. At the global level, our models revealed that carnivore richness and occupancy within study areas was positively associated with prey availability. Occupancy within study areas also tended to increase with greater protection and greater distances to roads. The strength of these relationships, however, differed among countries.

Main conclusions: We developed a research framework for leveraging global camera trap data to evaluate patterns of mammalian carnivore occurrence and richness across multiple spatial scales. Our research highlights the importance of intact prey populations and protected areas in conserving carnivore communities. Our research also highlights the potential of camera traps for monitoring wildlife communities and provides a case study for how this can be achieved on a global scale. We encourage greater integration and standardization among camera trap studies worldwide, which would help inform effective conservation planning for wildlife populations both locally and globally.

\section{KEYWORDS}

big data analysis, camera trap, carnivore, global, hierarchical Bayesian models, multispecies modelling, species occurrence, species richness

\section{1 | INTRODUCTION}

Biodiversity loss, species-level extinction risks and anthropogenic pressures on ecosystems are accelerating (Alkemade et al., 2009; Butchart et al., 2010). Biodiversity loss, specifically, will rank among the major drivers of ecosystem change in the 21st century, comparable to warming climate and increased nitrogen deposition (Hooper et al., 2012). To address these alarming trends, the Convention on Biological Diversity developed a strategic plan, signed by 193 nations, aimed at conserving, restoring and wisely using biodiversity [Secretariat of the Convention on Biological Diversity (SCBD), 2014]. However, the infrastructure required to measure changes in biodiversity, such as trends in abundance or changes in species' distributions, is often lacking, thereby limiting our ability to monitor progress towards achieving Convention goals (Ahumada, Hurtado, \& Lizcano, 2013; Schmeller et al., 2015). Additionally, collaborative research aimed at monitoring biodiversity internationally is rare, which makes effective conservation planning across geopolitical borders challenging (Feeley \& Silman, 2011). The increasingly urgent need to address major environmental challenges and prioritize conservation actions has led to calls for coordinated global monitoring networks (Ellison, 2010; Kelling et al., 2009; Schmeller et al., 2015; Steenweg et al., 2017).

Leveraging the existing biodiversity data would also aid in the development of effective, science-driven environmental policies across multiple spatial scales (Hampton et al., 2013; Jones, Schildhauer, Reichman, \& Bowers, 2006; Kelling et al., 2009; O'Brien, Baillie, Krueger, \& Cuke, 2010; Schmeller et al., 2015). The challenge is not in the availability of biodiversity data, an abundance of which is collected annually. Instead, efforts are hampered by limited exchange and aggregation of these data and the need for common data and analysis formats (Ellison, 2010; Jones et al., 2006). Organizing and analysing large, heterogeneous datasets is challenging. Data often suffer from observational biases, differences in sampling effort and differing levels of training (Ahumada et al., 2013; Hampton et al., 2013; Kelling et al., 2009). Even when common protocols are used, researchers need to be willing to work collaboratively and share data (Hampton et al., 2013; Kelling et al., 2009). Successful implementation of global biodiversity monitoring networks therefore requires international collaboration and welldocumented data collected in standardized formats with standardized metadata (Hampton et al., 2013).

Camera traps offer a potential method for monitoring biodiversity, because they provide standardized data that can be integrated across multiple regions using an occupancy modelling framework (Rich, Miller, Robinson, McNutt, \& Kelly, 2016). Remote cameras detect animals using motion- and heat-sensing infrared technology, providing records of detections for a wide diversity of species, living in a broad range of ecosystems, at any time of day or year. Each photographic detection includes records of the time, date and location of the photograph. 
These data allow researchers to account for species' detection probabilities (i.e., the probability a species was present but went undetected) using occupancy models (MacKenzie et al., 2002). The ability to account for observation error allows results to be compared across species, sites and years. Consequently, this method has been used to evaluate species' distributions, community richness, temporal activity patterns, occupancy trends and intra- and interspecific interactions (Ahumada et al., 2011; Burton et al., 2015; O'Brien et al., 2010; Steenweg et al., 2017). Recently, occupancy modelling has been extended to a multi-region community model that accommodates data collected across multiple regions of interest. This permits species richness and species-specific occupancy to be modelled as a function of regionspecific covariates (Miller \& Grant, 2015). Owing to this recent advancement, camera traps may now serve as a tool for addressing broad-scale ecological inquiries, such as monitoring understudied carnivore communities on a global scale.

Camera traps are especially useful for monitoring mammalian carnivores, because they are difficult to count directly owing to their generally low density and elusive nature. Nearly one-quarter of the world's 245 carnivore species are threatened with extinction and many more are experiencing population declines (Ripple et al., 2014; Schipper, Hoffmann, Duckworth, \& Conroy, 2008). Among the 31 largest carnivores, 19 are listed as threatened by the International Union for the Conservation of Nature (IUCN) and 24 are decreasing in number. The unremitting decline of many of our world's carnivores is a threat not only to these species, but also to the ecosystems in which they reside. Carnivore declines have led to changes in plant diversity, biomass and productivity, which are likely to impact nearly all other species and ecological processes, such as nutrient cycling, frequency of wildfires, and carbon sequestration (Ripple et al., 2014). To curtail the decline of our world's remaining carnivore species, a better understanding of the global drivers of carnivore communities is vital.

A diverse range of anthropogenic and environmental variables interact to determine the spatial distributions of carnivore communities. Among these variables, one of the most fundamental is the availability of prey resources (Carbone \& Gittleman, 2002; Farris et al., 2015; Fuller \& Sievert, 2001; Henden, Stien, Bårdsen, Yoccoz, \& Ims, 2014; Karanth et al., 2004). Carnivores are also known to be positively associated with permanent water sources (Epps, Mutayoba, Gwin, \& Brashares, 2011; Schuette, Wagner, Wagner, \& Creel, 2013) and with vegetation cover and productivity, probably because of their relationship with prey abundance (Pettorelli et al., 2005). These environmental features are increasingly altered as a consequence of the ever-growing human population and the corresponding demand for land. Thus, landuse change, fragmentation and infrastructure development continue to pose some of the greatest threats to biodiversity worldwide (Alkemade et al., 2009) and negatively affect carnivore distributions and densities. Roads, for example, can alter animal movements, fragment ecosystems and lead to increases in both legal and illegal hunting pressure (Forman \& Alexander, 1998). Threats posed by human development are particularly acute for carnivores given their protein-rich diet, large home range sizes and low densities, as well as the real or perceived threats carni- vores engender to humans and their livelihoods (Woodroffe \& Ginsberg, 1998). Understanding how natural and anthropogenic drivers determine carnivore distributions is key to mitigating their declines.

We used a new approach for investigating patterns in mammalian carnivore occupancy and richness at multiple spatial scales. Our research was motivated by the recent call for coordinated global monitoring networks (Steenweg et al., 2017) and provides a case study for how this can be achieved. We collated camera trap data from surveys conducted in 12 countries, which include observations of 96 carnivore species (c. $40 \%$ of the world's extant carnivore species), ranging in size from the long-tailed weasel (Mustela frenata; c. $0.27 \mathrm{~kg}$ ) to the grizzly bear (Ursus arctos; c. $340 \mathrm{~kg}$ ). Over half of these species had decreasing $(n=47)$ or unknown $(n=8)$ population trends according to the IUCN. Our common framework allowed us to integrate data collected by multiple international organizations, including universities, federal agencies and non-governmental organizations. Our objectives were to quantify (a) mammalian carnivore occupancy and species richness at the locallevel, and (b) anthropogenic and environmental variables that affected these patterns at global, local and species-specific levels. By examining patterns at a global scale, we can evaluate the interchange between fine- and broad-scale processes, which is vital in understanding ecosystem dynamics (Peters et al., 2008) and in assessing global, regional and local threats to carnivore communities (Ahumada et al., 2011; O'Brien et al., 2010).

\section{2 | METHODS}

\subsection{Study areas}

Our analysis integrated local monitoring efforts spanning five continents, with study area sizes ranging from 42 to $18,714 \mathrm{~km}^{2}$ (Table 1; Figure 1). In North America, we included studies carried out in five national parks in western Canada, ranging from Jasper National Park in the north to Waterton Lakes National Park in the south (Steenweg et al., 2016), the Sierra Nevada mountains of California in the U.S.A. (Tucker, Schwartz, Truex, Wisely, \& Allendorf, 2014) and the protected Mayan forest in Belize (Wultsch, Waits, \& Kelly, 2016). In South America, we included studies from the Atlantic Forest of Misiones Province in northeastern Argentina (Di Bitetti, Paviolo, \& De Angelo, 2006) and the Yungas ecoregion in northwestern Argentina (Di Bitetti, Albanesi, Foguet, Cuyckens, \& Brown, 2011). We analysed the two study areas in Argentina separately because they were independent studies carried out in vastly different ecosystems. In Africa, studies were located in the Cederberg mountains of Western Cape, South Africa (Martins, 2010), Ngamiland District of northern Botswana (Rich et al., 2016), Niokolo Koba National Park of Senegal (Kane, Morin, \& Kelly, 2015) and the Masoala-Makira protected landscape of Madagascar (Farris et al., 2015). In Asia, we included studies from the southern Riau landscape of central Sumatra in Indonesia (Sunarto, Kelly, Parakkasi, \& Hutajulu, 2015), the Churia habitat in Chitwan National Park in the south-central Terai Arc in Nepal (Thapa \& Kelly, 2017) and seven reserves across central Iran (Farhadinia et al., 2014). Lastly, in Europe, we included a study carried out in four peninsulas along the 


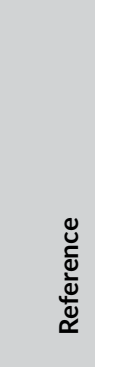

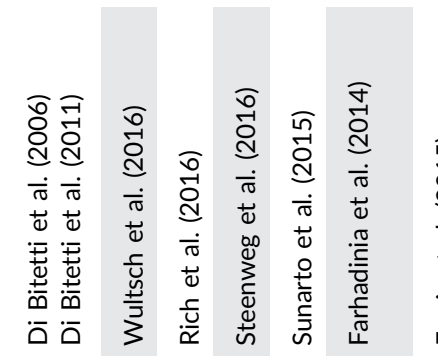

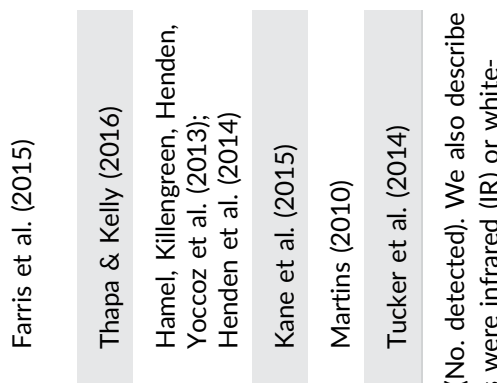

II

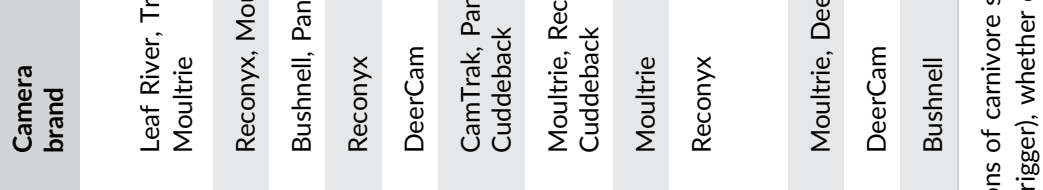

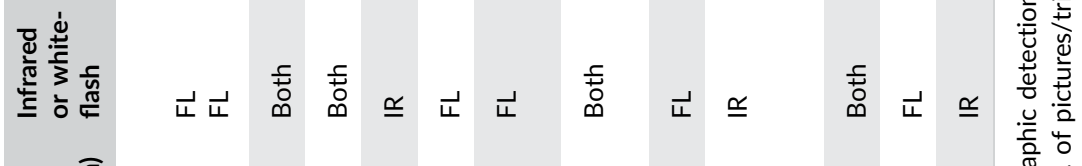

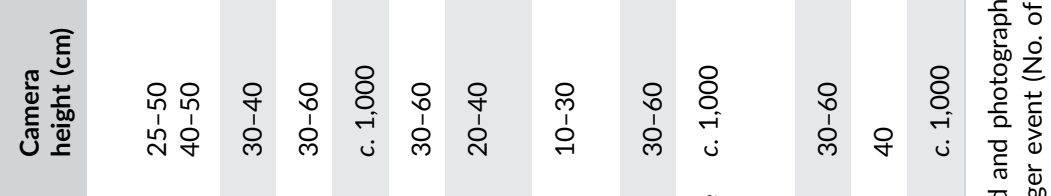

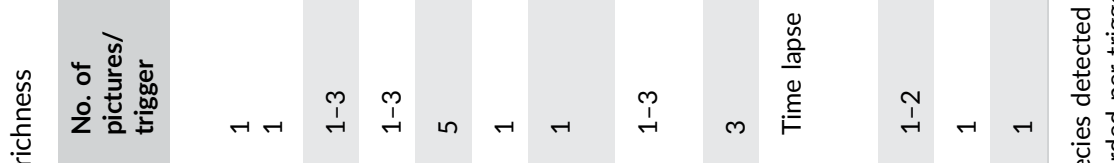



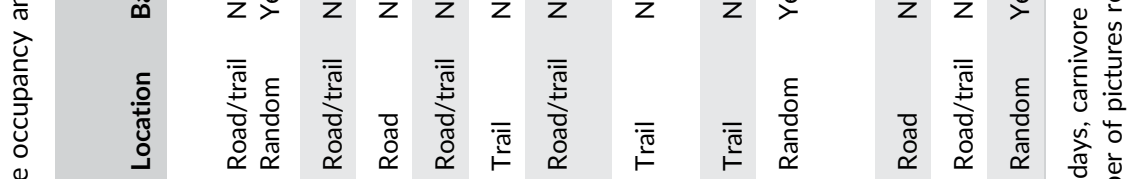

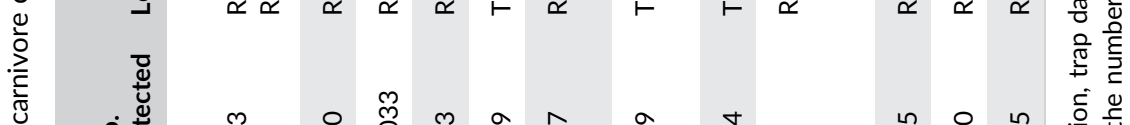

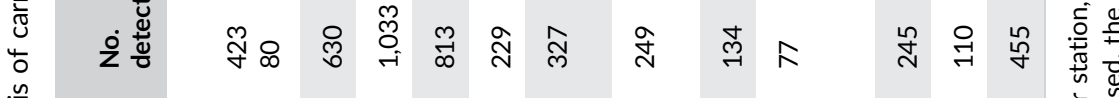

$\frac{\frac{\pi}{n}}{\frac{\pi}{\pi}}$

幽

ஸั๊

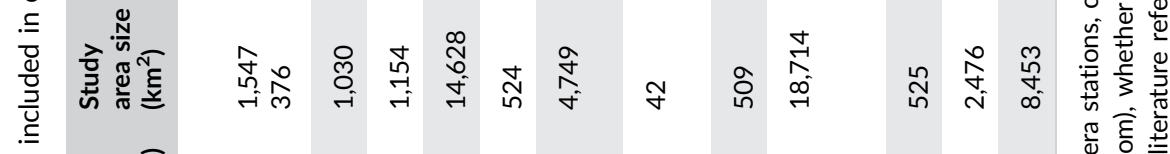

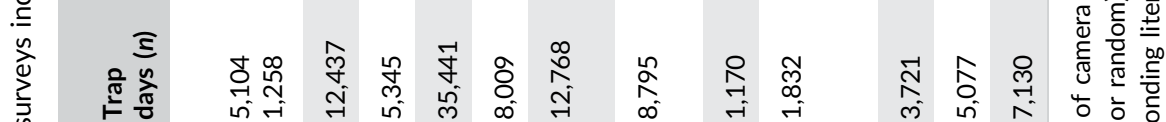

焉





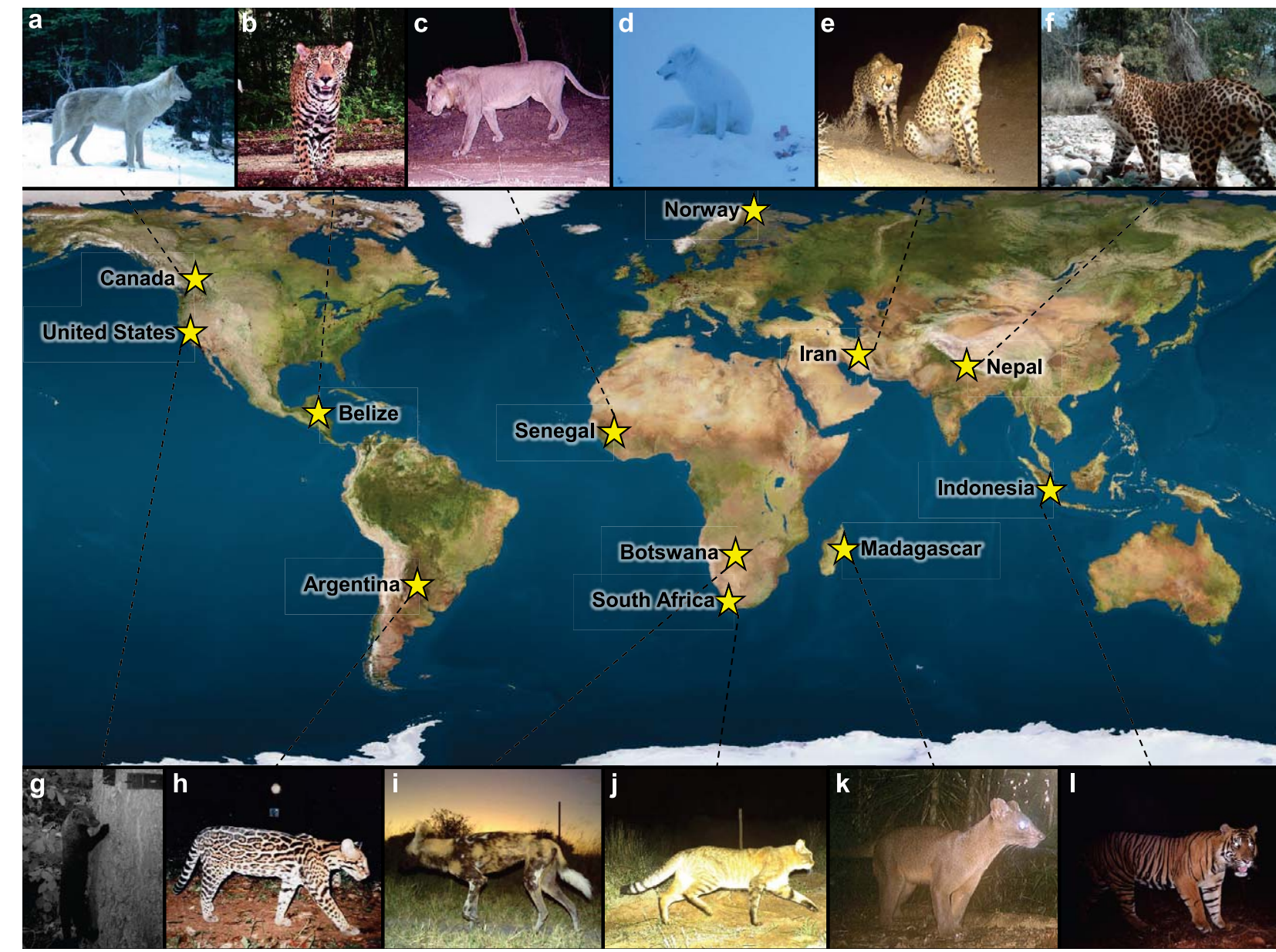

FIGURE 1 Relative locations of the local camera trap projects included in a global carnivore analysis. Examples of carnivores included in the study are as follows: (a) grey wolf (Canis lupus; ( ) R. Steenweg), (b) jaguar (Panthera onca; ( ) M. Kelly), (c) lion (Panthera leo; ( ) M. Kane), (d) arctic fox (Vulpes lagopus; ( S. Killengreen), (e) Asiatic cheetah (Acinonyx jubatus venaticus; @ Iranian Cheetah Society/CACP/DoE/ Panthera), (f) leopard (Panthera pardus fusca; (c K. Thapa/WWF), (g) fisher (Pekania pennant; @ J. Tucker/U.S. Forest Service), (h) ocelot (Leopardus pardalis; @ M. Di Bitetti), (i) African wild dog (Lycaon pictus; @ L. Rich/Panthera), (j) wildcat (Felis silvestris; @ Q. Martins/Cape Leopard Trust), (k) fossa (Cryptoprocta ferox; @ Z. Farris), and (I) Sumatran tiger (Panthera tigris sumatrae; ( S. Sunarto/WWF)

coast of Finnmark in northern Norway (Hamel, Killengreen, Henden, Yoccoz, \& Ims, 2013; Henden et al., 2014).

\section{2 | Camera trap surveys}

A diversity of camera trap makes and models were used, including both infrared and white-flash cameras (Table 1). All surveys were completed between 2005 and 2015 (Table 1). Within each study area, 22-319 $(\bar{x}=143 ; S D=85.5)$ camera stations were deployed across areas ranging in size from $42 \mathrm{~km}^{2}$ in Madagascar to $18,714 \mathrm{~km}^{2}$ in Norway $(\bar{x}=4,210 ; S D=6,053$; Table 1). Studies had a minimum of 1,000 trap days, with the number of trap days ranging from 1,170 to 35,441 $(\bar{x}=9,007 ; S D=8,981 ;$ Table 1$)$.

\section{$2.3 \mid$ Covariates}

We hypothesized that the spatial distributions of mammalian carnivores may be influenced by both anthropogenic and environmental variables. Our anthropogenic variables included the level of protection and the distance to a major road. We used an ordinal variable ranging from one to three indicating whether the camera station was located in a fully protected, partly protected or unprotected area, respectively, to represent level of protection. Fully protected areas included national parks, reserves and sanctuaries; partly protected areas included community-run wildlife areas and protected areas that permitted some multiple use; and unprotected areas included logging, hunting, livestock grazing and/or farming areas. Next, we used a global roads dataset from the Center for International Earth Science Information Network and Information Technology Outreach Services (CIESIN \& ITOS, 2013) to measure the distance from each camera station to the nearest major road using ArcMap 10.3.1 (ESRI, CA). Mean and SD values for covariates within each of the respective study areas are presented in Appendix S1 in Supporting Information.

Our environmental variables included prey availability, distance to water, and forest cover (Supporting Information Appendix S1). To represent relative prey availability, we used the detection rate of non- 
carnivorous vertebrates at each camera station. The detection rate was equal to the number of independent detections of a non-carnivorous vertebrate standardized by sampling effort (i.e., number of days the camera station was active). We defined independent detections of a prey species as photo events separated by $\geq 30$ min unless different individuals could be distinguished (e.g., five individuals in a single photograph would be five events). We used this measure of relative prey availability, rather than estimates of prey occupancy, because it provided more detailed information regarding the local activity levels of prey species. However, we note that our measure did not account for species-specific detection probabilities. To estimate distance to water, we used the world water bodies layer from Esri Data and Maps (2011) and calculated the distance (in kilometres) from each camera station to the nearest body of water. The water layer did not account for smaller bodies of water, such as streams, ponds and ephemeral water sources. Consequently, the geographic information system (GIS) layer did not include any bodies of water for Senegal. Lastly, to determine forest cover, we used a $250 \mathrm{~m}$ resolution moderate-resolution imaging spectroradiometer (MODIS) dataset, based on data from 2000-2010, that contained proportional estimates for forest, grassland and bare ground cover (DiMiceli et al., 2011). We determined mean percentage forest cover within a $1 \mathrm{~km}^{2}$ buffered area surrounding each camera station. All of our covariates were relatively coarse, but they allowed us to use consistent and comparable values across all study areas.

\section{4 | Modelling framework}

We used multispecies occupancy models to estimate species-specific occurrence probabilities in each study area, while correcting for incomplete detection (Dorazio \& Royle, 2005). Correcting for incomplete detection (i.e., instances when a species is present but not photographed) requires spatially or temporally replicated data. As is common for camera trap studies, we treated each trap day as a repeat survey at a particular camera station (Rich et al., 2016). In addition to species' detection, our hierarchical model structure allowed us simultaneously to account for spatial variation in model parameters using a mixed modelling approach with random effects to accommodate camera station and study area-level influences on species occurrence (Miller \& Grant, 2015). We estimated the probability of observing species $i$ at camera station $j$ on trap day $k$ conditional on the site being occupied as $x_{i, j, k} \sim \operatorname{Bern}\left(p_{i, j, k}{ }^{*} z_{i, j}\right)$. The detection probability, $p_{i, j}$, $k$, was the probability species $i$ was photographed at camera station $j$ during trap day $k$, given species $i$ was truly present at camera station $j$. Occurrence, $z_{i, j}$, was a latent binary variable where $z_{i, j}=1$ if camera station $j$ was within the range occupied by species $i$ and 0 otherwise, and modelled as a Bernoulli random variable, $z_{i, j} \sim \operatorname{Bern}\left(\psi_{i j}\right)$, where $\psi_{i j}$ is the probability that species $i$ occurred at camera station $j$ (MacKenzie et al., 2002).

We first fitted the occurrence model separately for each study area. We incorporated site-level (i.e., camera station-specific) characteristics affecting species-specific occurrence probabilities using a generalized linear mixed modelling approach (Dorazio \& Royle, 2005). For each study area, occurrence probability for species $i$ at camera station $j$ was specified as follows:

$$
\begin{aligned}
\operatorname{logit}\left(\psi_{i j}\right)= & \beta 0_{i}+\beta 1_{i}(\text { level of protection })_{j}+\beta 2_{i}(\text { distance to roads })_{j} \\
& +\beta 3_{i}(\text { prey detection rates })_{j}+\beta 4_{i}(\text { forest cover })_{j} \\
& +\beta 5_{i}(\text { distance to water })_{j}
\end{aligned}
$$

We log transformed continuous covariates; then for each of the study areas, we standardized all covariates to have a mean of 0 and $S D$ of 1 . Therefore, the inverse logit of $\beta \mathrm{O}_{i}$ was the occurrence probability for species $i$ at a camera station with average covariate values within the respective study area. Remaining coefficients $\left(\beta 1_{i}, \ldots, \beta 5_{i}\right)$ represent the effect of a one $S D$ increase in the covariate value for species $i$. This approach allows covariate relationships to be comparable across study areas. We note, however, that the magnitude of the relationships is study area specific because SD estimates varied across countries (Supporting Information Appendix S1). Detection probability $p$ was allowed to differ using a species-specific random effect, which was drawn from a logit-normal distribution. In many cases, the density of a species is related to both the overall occupancy probability and the average site-specific detection probability, resulting in strong, positive correlations between occupancy and detection among species (Royle \& Nichols, 2003). Therefore, we accounted for correlation ( $\rho$ ) between $\beta \mathrm{O}_{i}$ in the occupancy model and the species-specific detection parameter $\left[\alpha 0_{i}\right.$, where logit $\left.(p)=\alpha \mathrm{O}_{i}\right]$ by specifying the two parameters to be jointly distributed (Dorazio \& Royle, 2005).

For each of our occurrence models ( $n=13$ models representing 13 study areas), we linked species-specific responses using speciesspecific random effects for intercept and slope parameters. Sharing data across species leads to increased precision in estimates of speciesspecific occupancy, particularly for rare and elusive species (Zipkin, Royle, Dawson, \& Bates, 2010), and provided a framework for estimating average effects and precision across the local carnivore community. Specifically, for each occurrence model, the $\beta$ coefficients were modelled as $\beta_{i} \sim \operatorname{normal}\left(\mu_{\beta}, \sigma_{\beta}^{2}\right)$, where $\mu_{\beta}$ is the community-level mean and $\sigma^{2}{ }_{\beta}$ is the variance (Chandler et al., 2013). Thus, $\beta$ coefficients were functions of both the community-level hyper-parameter and the species-specific effect for the respective covariate.

We estimated posterior distributions of parameters using Markov chain Monte Carlo (MCMC) implemented in JAGS (version 3.4.0), which we called using R2Jags (Plummer, 2011) in R (R Core Development Team 3.2.2). We generated three chains of 50,000 iterations after a burn-in of 10,000 iterations and thinned by three. Priors for each of the hyper-parameters included the following: a uniform distribution of $0-1$ on the real scale for $\beta 0_{i}$, a uniform distribution of $0-10$ for $\sigma$ parameters, and a normal distribution with a mean of 0 and SD of 100 on the logit scale for the remaining covariate effects $\left(\beta 1_{i}, \ldots, \beta 5_{i}\right)$. We assessed model convergence using the Gelman-Rubin statistic, where values $<1.1$ indicated convergence (Gelman, Carlin, Stern, \& Rubin, 2004).

Finally, we were also interested in estimating average covariate effects across all study areas (i.e., global-level effects) using a multiregion, multispecies model (Miller \& Grant, 2015). To do this, we 
TABLE 2 Global-level mean $(\bar{x})$ and $95 \%$ credible interval $(95 \% \mathrm{Cl})$ estimates for the covariates hypothesized to influence the occurrence probabilities of carnivores in study areas spanning 12 countries

\begin{tabular}{lccc} 
Covariate & $\overline{\boldsymbol{x}}$ & \multicolumn{2}{c}{$95 \% \mathrm{Cl}$} \\
\hline Level of protection $^{\mathrm{a}}$ & -0.36 & -2.753 & 0.585 \\
\hline Distance to roads & 0.11 & -0.072 & 0.293 \\
\hline Prey detection rates & 0.99 & 0.576 & 1.410 \\
\hline Forest cover & 0.13 & -0.500 & 0.759 \\
\hline Distance to water & 0.29 & -1.236 & 1.821
\end{tabular}

Note. Within each study area, we standardized all covariates to have a

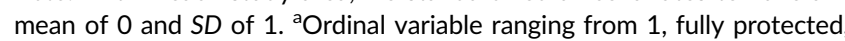
to 3 , unprotected. Only includes study areas that had cameras deployed across multiple land designations (excludes Yungas Argentina, Indonesia, Iran, Nepal and Senegal).

refitted data from all the study areas simultaneously, still including region-specific hyper-parameters for species-specific effects. This allowed us to estimate an average effect across all regions (and precision of this effect) by calculating the average of the $\mu_{\beta}$ parameters for each of the regions. Our approach allowed us to propagate uncertainty across the multiple hierarchical levels (site, species and region) when estimating an average global effect. We also used this model to generate estimates of species richness at the level of individual camera station $j$ by summing the number of estimated species at a site within each region during each of the model iterations. This allowed us to generate predicted mean species richness to facilitate comparisons of total predicted richness with respect to region and covariate values (Rich et al., 2016; Zipkin et al., 2010). Our model code is provided in Supporting Information Appendix S2.

\section{3 | RESULTS}

Our research included 4,805 detections of 96 mammalian species from the Order Carnivora, collected during $>100,000$ trap nights at $>1,700$ camera stations (Table 1). The mean recorded number of carnivore species per study area was 12 (Table 1), ranging from three species in Norway to 22 species in Botswana. The mean estimated occupancy across all species and countries was 0.31 (i.e., on average each species was estimated to occur at $31 \%$ of the sites within a study area where the species was known to occur; $S D=0.235$ ). Species-specific estimates of occupancy ranged from 0.02 for striped skunk (Mephitis mephitis) in Canada to 0.90 for spotted hyena (Crocuta crocuta) in Botswana. Given that we treated each trap day as a repeat survey, our estimated detection probabilities were low $(\bar{x}=0.04, S D=0.007)$ but highly variable among species, ranging from 0.002 for fisher (Pekania pennanti) in Canada to 0.21 for Pampas fox (Lycalopex gymnocercus) in Argentina. Species- and country-specific estimates of occupancy, detection and covariate effects are presented in Supporting Information Appendix S3.

At the global level, prey detection rate had the largest impact on carnivore occupancy probabilities, where carnivore occupancy increased as prey detection rates increased (Table 2). Occupancy also tended to increase in areas with greater protection and greater distance to major roads [i.e., $95 \%$ credible intervals $(\mathrm{Cls})$ overlapped 0.0 , but values were predominantly positive or negative], whereas no relationship was found with forest cover and distance to water (Table 2). There was, however, heterogeneity in the influences of covariates at the local level (Figure 2). For instance, the positive relationship between occupancy and prey detection rate was most evident in Nepal, Madagascar and Iran, but this relationship was negative in Norway and the U.S.A. (Figure 2; Supporting Information Appendix S4). The tendency for occupancy to increase with greater distance to roads was most evident in Norway, Madagascar and Indonesia, whereas carnivore occupancy tended to be higher close to major roads in Nepal and Senegal (Figure 2; Supporting Information Appendix S4). Among the local monitoring efforts that had cameras deployed across multiple land designations, the tendency for occupancy to increase in areas with greater protection was most evident in Norway, Canada and Belize (Figure 2; Supporting Information Appendix S4). The influence of forest cover was highly variable at the local level, with occupancy generally increasing with increasing forest cover in Indonesia, Canada and South Africa, and with decreasing forest cover in Senegal, Nepal and Botswana (Figure 2; Supporting Information Appendix S4). The influence of distance to a large body of water was weak, with the exception of Madagascar and Indonesia, where carnivore occupancy was greater in areas further from water bodies (Figure 2; Supporting Information Appendix S4).

Among all countries, our camera station-specific estimates of mammalian carnivore richness ranged from $0(95 \% \mathrm{Cl}=0-1)$ to 13 (95\% Cl $=11-15$ ), with a mean of 4 (Supporting Information Appendix S5). Mean carnivore richness (i.e., across all camera stations within the respective country) was greatest in Botswana $(\bar{x}=7.9)$ and the Misiones region of Argentina $(\bar{x}=5.9)$ and least in Norway $(\bar{x}=1.2)$ and Madagascar $(\bar{x}=2.0)$. At the global level, relative carnivore richness was mainly correlated with prey detection rates, with higher carnivore richness occurring in areas with higher prey density (Figure 3 ). The remaining covariates did not appear to influence camera stationspecific estimates of carnivore richness (Figure 3).

\section{4 | DISCUSSION}

At both global and local scales, our research supported the foundational ecological concept that prey availability is a fundamental determinant of carnivore distributions (Carbone \& Gittleman, 2002; Fuller \& Sievert, 2001). Detection rates of prey (i.e., non-carnivorous vertebrates) had the strongest and consistently positive influence on mammalian carnivore occupancy and carnivore richness across the wide diversity of ecosystems included in our study, with the exception of only two study areas (Figure 2). Positive relationships between carnivores and their prey have been found in studies spanning the globe and for species ranging from broad-striped vontsira (Galidictis fasciata; Farris et al., 2015) to wolverines (Gulo gulo; Henden et al., 2014) and tigers (Panthera tigris; Karanth et al., 2004). Our measure of prey availability was camera station specific to reflect spatial variation in prey 

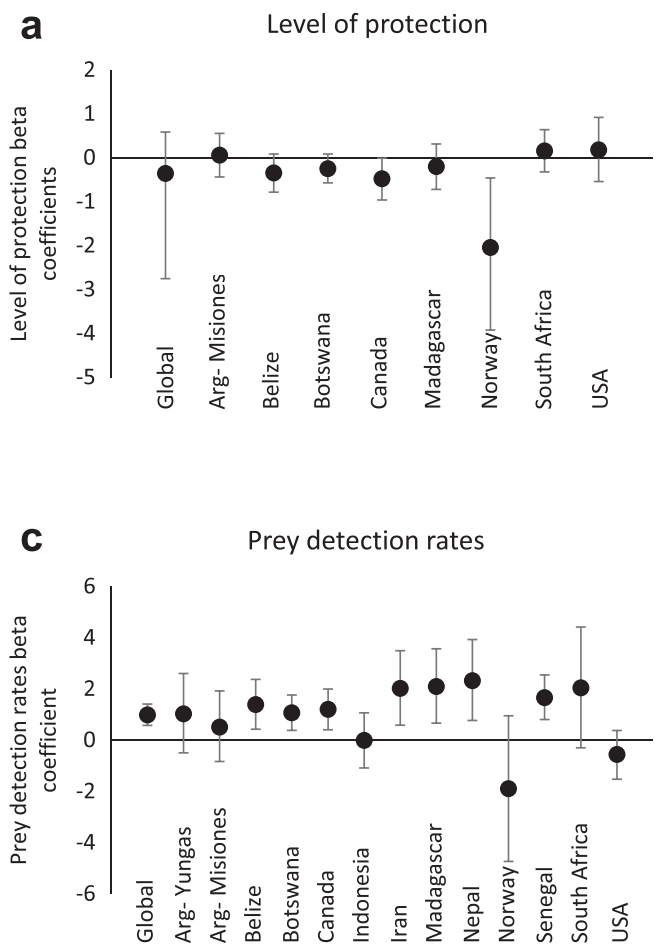

b

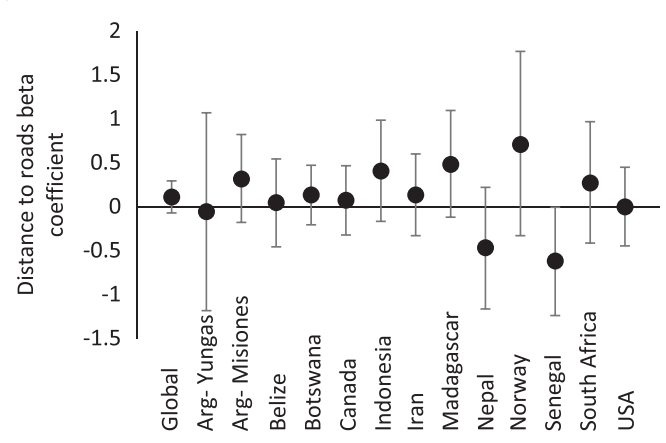

d

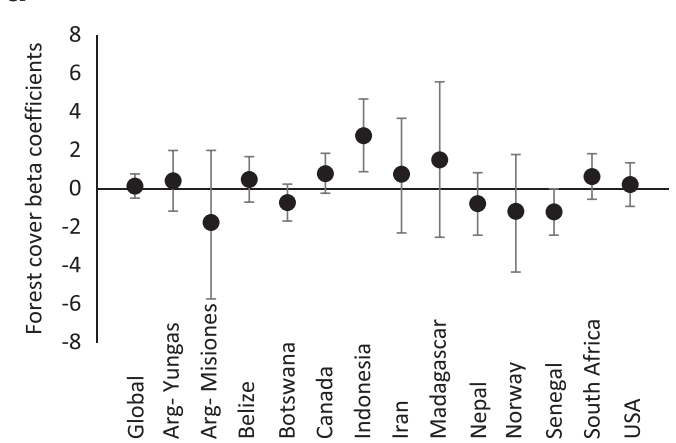

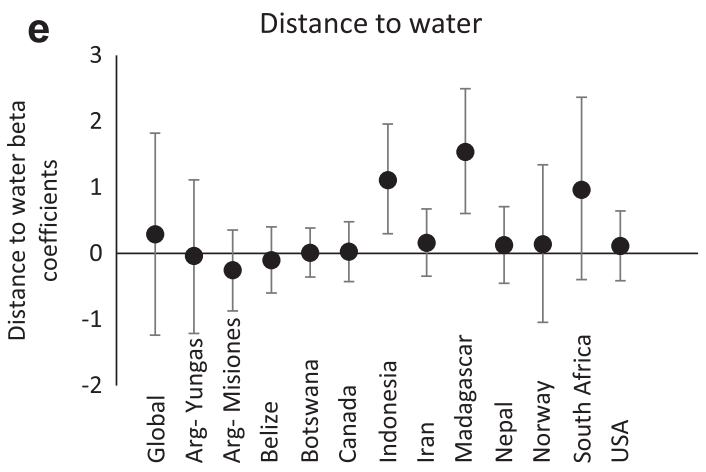

FIGURE 2 Standardized $\beta$ coefficients, and 95\% credible intervals, for the influence of (a) level of protection as represented by an ordinal variable ranging from one (fully protected) to three (unprotected), (b) distance to major roads, (c) prey detection rates (mean number of detections of non-carnivorous vertebrates per trap night), (d) percentage forest cover, and (e) distance to a major water source, on the probability a carnivore species used an area during camera trap surveys carried out in 13 study areas and the mean effect on carnivore occupancy across all study areas (global)

resources (Fuller \& Sievert, 2001) and to help ensure that it was comparable across local monitoring efforts.

Although the relationship between observed prey and carnivore richness was clear, there were some limitations to how we measured prey availability. We did not account for prey detectability, treated all prey species as equivalent, and did not include important components of many carnivore diets (e.g., small mammals, invertebrates, fish and fruit). In the U.S.A., for example, many carnivores consume a wide variety of food items; thus, the prey species photographed most often (chipmunks and squirrels) represented only a fraction of their diets (Zielinski \& Duncan, 2004). This incongruence is particularly true for the most commonly detected carnivore species in the region, black bears (Ursus americanus), and helps to explain the negative relationship we found between carnivore occupancy and prey availability in the U.S.A.
The negative relationship in Norway may be design related. The Norway study baited cameras with reindeer (Rangifer tarandus) slaughter remains to increase carnivore detection probabilities (Henden et al., 2014). This might have resulted in lower prey detection rates that were unrepresentative of regional prey abundance. Indeed, Henden et al. (2014) found that reindeer density, estimated from aerial surveys, was generally positively associated with carnivore distributions in Norway. Despite these limitations, our research still supported the vital role prey populations play in maintaining carnivore communities across a broad range of ecosystems (Carbone \& Gittleman, 2002; Fuller \& Sievert, 2001).

At the global level and for several of the study areas, mammalian carnivore occupancy also tended to be greater in areas with higher levels of protection (e.g., national parks and reserves) that were further 
a

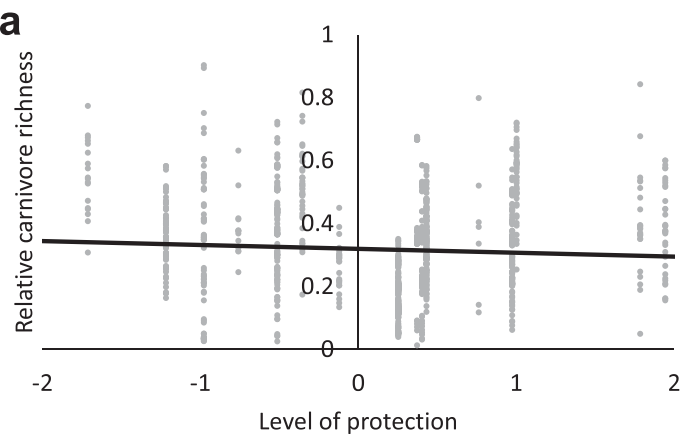

C

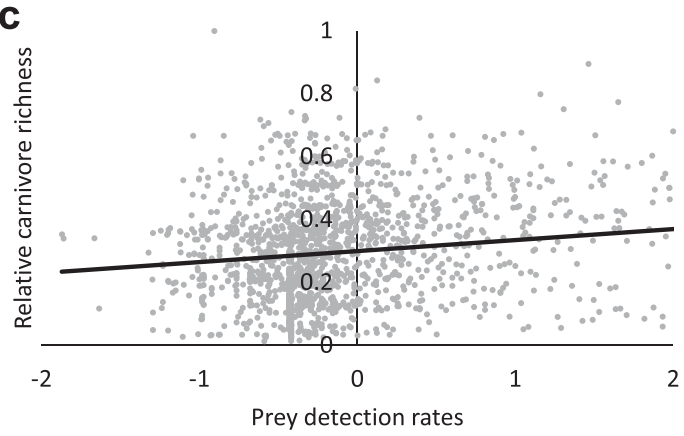

b

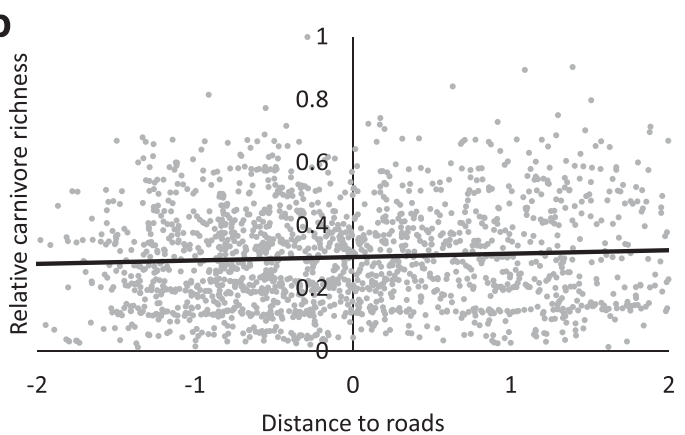

d

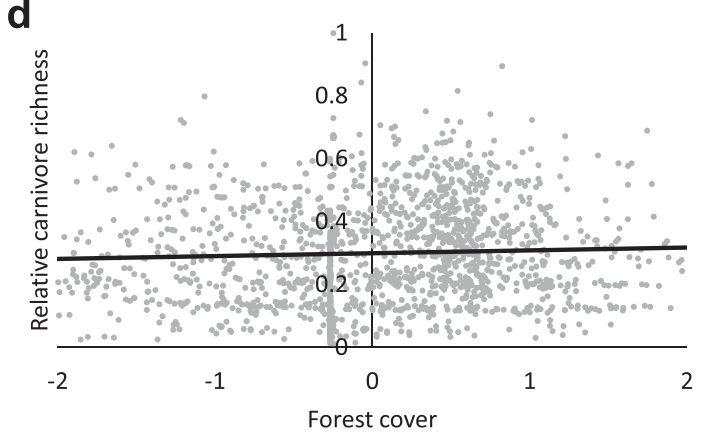

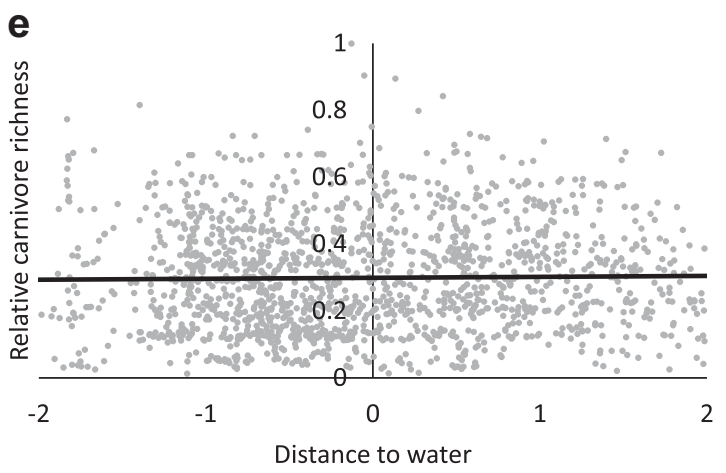

FIGURE 3 Relative carnivore richness (estimated richness at camera station/number of carnivore species photographed in respective study area) at 1,714 camera stations located across 13 study areas in relationship to (a) level of protection (ordinal variable where $1=$ fully protected and $3=$ unprotected), (b) distance from camera station to a major road, (c) prey detection rate (mean number of detections of non-carnivorous vertebrates per trap night), (d) percentage forest cover, and (e) distance from the camera station to a major water source. Covariate values were standardized within each study area to have a mean of 0 and SD of 1

from major roads (Figure 2). Our results are consistent with studies showing that human development negatively affects biodiversity worldwide (Alkemade et al., 2009; Butchart et al., 2010). Additionally, our finding that carnivore occupancy generally increased as the level of protection increased supports studies highlighting the important role protected areas play in conserving wildlife populations (Bertzky et al., 2012; Watson, Dudley, Segan, \& Hockings, 2014). Maintaining, expanding and effectively managing these areas is crucial to the conservation of carnivore diversity as well as to safeguarding landscapes and protecting essential ecosystem services (Bertzky et al., 2012; Watson et al., 2014). Our measure of protection was broad and did not fully encompass the effects that differences in habitat quality, enforcement of protected area boundaries or types of human activity (e.g., logging versus agriculture) might have on carnivore populations. Likewise, our measure of distance to roads was coarse; it did not include smaller, four-wheel drive roads, and we treated all roads as equal. With better information on the level of protection and road characteristics, important nuances and greater power to detect relationships might emerge. Regardless, our results generally point to the role of areas that are protected and far from major roads in supporting carnivore diversity (Table 2), which adheres to the over-arching negative effect of human activity on carnivore species (Alkemade et al., 2009; Butchart et al., 2010).

Distance to water and forest cover were highly variable in their effects both within and among study systems. Several species, such as servals (Leptailurus serval), African civets (Civittictis civetta) and lions (Panthera leo) in Botswana, were more likely to occupy areas close to major water sources (Supporting Information Appendix S3). Generally, however, water was related only weakly to carnivore occupancy. This was probably a consequence of the ability of carnivores to travel long distances and the diversity of ecosystems included in our analysis. Additionally, we may have been limited by our need to relate patterns 
to a global water layer, which did not account for smaller bodies of water, such as streams, ponds and ephemeral water sources. These smaller sources of water are common in many of the areas and potentially easier to access. The highly variable influence of forest cover was also a consequence of the diversity of ecosystems included in our research, ranging from tropical forests to the arctic tundra. The variation in the effects of forest cover on carnivore occupancy highlights the importance of tailoring conservation strategies to the particular ecosystem of interest.

Our approach allowed us to determine factors related to carnivore richness that were consistent across regions (e.g., prey availability and, to a lesser extent, protection status and distance to roads) but also when relationships varied among regions. In general, we expect that global-scale results will not be reliable proxies for local-scale processes when (a) heterogeneity is large and not well described by a statistical distribution, (b) the way relationships scale with respect to the same covariate differs among locations, and (c) the processes that affect distributions differ among study areas. In the present study, we have taken a first large step to reduce heterogeneity by accounting for observation bias and by including random effects to help accommodate the diversity of study designs. However, our analysis was limited in that all of the covariates we included were relatively coarse. As technology continues to improve, the resolution of available data is becoming finer and and the spatial coverage broader. We encourage future studies to build upon and improve our global assessment by using this anthropogenic and environmental data to capture heterogeneity better at the local level. Our global assessment could also be improved by accounting for differences among areas in the structure of the respective carnivore guilds (i.e., size and type of carnivores). This might be important, because covariates such as the level of protection, for example, could affect generalist species in a different way from specialists. Lastly, to gain a full understanding of the influence of covariates, we encourage future studies to continue presenting both global and local estimates. This is important because the mean, global estimate might be unrepresentative if the influence of covariates is not linear or the strength of these effects differs across studies (e.g., opposing effects of forest cover on forest versus savanna carnivore assemblages).

Collaborative and integrative biodiversity monitoring is necessary to develop effective conservation planning and to mitigate biodiversity loss (Ellison, 2010; Jones et al., 2006; Schmeller et al., 2015). Our research demonstrates that when researchers are willing to work collaboratively and share data, broad-scale assessments are possible. Our research also highlights the potential of camera traps as a tool for monitoring global biodiversity in accordance with the Convention on Biological Diversity (Ahumada et al., 2013; Burton et al., 2015; O'Brien et al., 2010; Steenweg et al., 2017). With the exponential increase in the use of camera traps over the last decade, there is further opportunity to standardize methods in ways that would increase their utility for continental and global assessments. Given that the design of a camera trap study can greatly influence results (Hamel, Killengreen, Henden, Eide, et al., 2013), monitoring should aim to increase consistency among study areas. This should include standardization of sampling design, field methods (e.g., placement of cameras), and minimal standards for spatial and temporal extent. By developing a standardized design that targets all species or a specified subset, we can improve inferences on species diversity and richness at the global scale. Lastly, by avoiding heterogeneity in data collection across time, we will be better equipped to assess and quantify temporal trends. Greater integration and standardization among camera trap studies worldwide is key in developing a global biodiversity monitoring network (Steenweg et al., 2017). This would allow policy-makers and managers to track, improve and adapt policies and management actions aimed at addressing the loss of wildlife populations at both local and global scales (Butchart et al., 2010; Schmeller et al., 2015). Our research framework provides a starting point and blueprint for how this can be achieved on an international scale for carnivores.

\section{ACKNOWLEDGMENTS}

We thank the Ministry of the Environment, Wildlife and Tourism, the Department of Wildlife and National Parks and the Botswana Predator Conservation Trust in Botswana; the Ministry of Environment, Water, Forest and Tourism and Wildlife Conservation Society in Madagascar; the Department of National Parks and United States Agency for International Development/Wula Nafaa Project in Senegal; and The Cederberg Conservancy and CapeNature in South Africa for permission and/or supporting the research in Africa. In North America, we thank Parks Canada staff for collecting data in Canada and the National Science Foundation for funding part of this project (Long Term Research In Environmental Biology Grant 1556248); the Pacific Southwest Region of the U.S. Forest Service and the Sierra and Sequoia National Forests for supporting research in the U.S.A.; and in Belize, we thank the Forest Department, Programme for Belize, Las Cuevas Research Station, Bull Run Farm, Belize Audubon Society, Wildtracks, Gallon Jug Estate and Yalbac Ranch. In South America, we thank the Ministry of Ecology and Natural Resources of Misiones, the National Parks Administration of Argentina, Fundación Proyungas, Ledesma S.A. and ARAUCO Argentina S.A. for permissions and support to conduct camera trap surveys. In Asia, we thank the Iran Department of Environment for permission to work within the reserves in Iran, the World Wildlife Fund, the National Trust for Nature Conservation, Chitwan National Park and Department of National Parks and Wildlife Conservation for permission and support to survey in Nepal; and in Indonesia, World Wildlife Fund Networks, U.S. Fish \& Wildlife Service and the Hurvis Family for financially supporting the research, the Indonesian Ministry of Forestry for permission to conduct the study, and the World Wildlife Fund Team for all their support. Lastly, in Europe we thank the Directorate for Nature Management and The Norwegian Research Council for financing the camera trap data collected in Norway. Thank you to H. S. Robinson for help during the planning stages of the manuscript.

\section{REFERENCES}

Ahumada, J. A., Hurtado, J., \& Lizcano, D. (2013). Monitoring the status and trends of tropical forest terrestrial vertebrate communities from camera trap data: A tool for conservation. PLoS One, 8, e73707. 
Ahumada, J. A., Silva, C. E. F., Gapjapersad, K., Hallam, C., Hurtado, J., Martin, E., ... Andelman, S. J. (2011). Community structure and diversity of tropical forest mammals: Data from a global camera trap network. Philosophical Transactions of the Royal Society B: Biological Sciences, 336, 2703-2711.

Alkemade, R., van Oorschot, M., Miles, L., Nellemann, C., Bakkenes, M., \& Brink, B. (2009). GLOBIO3: A framework to investigate options for reducing global terrestrial biodiversity loss. Ecosystems, 12, 374-390.

Bertzky, B., Corrigan, C., Kemsey, J., Kenney, S., Ravilious, C., Besancon, C., \& Burgess, N. D. (2012). Protected planet report: Tracking progress towards global targets for protected areas. Cambridge, U.K.: International Union for Conservation of Nature and United Nations Environment Programme-World Conservation Monitoring Centre.

Burton, A. C., Neilson, E., Moreira, D., Ladle, A., Steenweg, R., Fisher, J. T., ... Boutin, S. (2015). Wildlife camera trapping: A review and recommendations for linking surveys to ecological processes. Journal of Applied Ecology, 52, 675-685.

Butchart, S. H. M., Walpole, M., Collen, B., van Strien, A., Scharlemann, J. P., Almond, R. E., ... Watson, R. (2010). Global biodiversity: Indicators of recent declines. Science, 328, 1164-1168.

Carbone, C., \& Gittleman, J. L. (2002). A common rule for the scaling of carnivore density. Science, 295, 2273-2276.

Center for International Earth Science Information Network (CIESIN), Columbia University, and Information Technology Outreach Services (ITOS), University of Georgia. (2013). Global roads open access data set, version 1. Retrieved from https://doi.org/10.7927/H4VD6WCT

Chandler, R. B., King, D. I., Raudales, R., Trubey, R., Chandler, C., \& Chávez, V. J. A. (2013). A small-scale land-sparing approach to conserving biological diversity in tropical agricultural landscapes. Conservation Biology, 27, 785-795.

Di Bitetti, M. S., Albanesi, S., Foguet, M. J., Cuyckens, G. A. E., \& Brown, A. (2011). The Yungas Biosphere Reserve of Argentina: A hot spot of South American wild cats. CAT News, 54, 25-29.

Di Bitetti, M. S., Paviolo, A., \& De Angelo, C. (2006). Density, habitat use and activity patterns of ocelots (Leopardus pardalis) in the Atlantic Forest of Misiones, Argentina. Journal of Zoology, 270, 153-163.

DiMiceli, C. M., Carroll, M. L., Sohlberg, R. A., Huang, C., Hansen, M. C., \& Townshend, J. R. G. (2011). MODIS vegetation continuous fields. Retrieved from http://glcf.umd.edu/data/vcf/

Dorazio, R. M., \& Royle, J. A. (2005). Estimating size and composition of biological communities by modeling the occurrence of species. Journal of American Statistical Association, 100, 389-398.

Ellison, A. M. (2010). Repeatability and transparency in ecological research. Ecology, 91, 2536-2539.

Epps, C. W., Mutayoba, B. M., Gwin, L., \& Brashares, J. S. (2011). An empirical evaluation of the African elephant as a focal species for connectivity planning in East Africa. Diversity and Distributions, 17, 603-612.

Esri Data and Maps. (2011). World water bodies. Retrieved from www.arcgis.com/home/item.html?id=e750071279bf450cbd510454a80f2e63

Farhadinia, M. S., Eslami, M., Hobeali, K., Hosseini-Zavarei, F., Gholikhani, N., \& Taktehrani, A. (2014). Status of Asiatic cheetah in Iran: A country-scale assessment (Project Final Report). Tehran: Iranian Cheetah Society (ICS).

Farris, Z. J., Golden, C. D., Karpanty, S., Murphy, A., Stauffer, D., Ratelolahy, F., ... Kelly, M. J. (2015). Hunting, exotic carnivores, and habitat loss: Anthropogenic effects on a native carnivore community, Madagascar. PLoS One, 10, e0136456.

Feeley, K. J., \& Silman, M. R. (2011). The data void in modeling current and future distributions of tropical species. Global Change Biology, 17, 626-630.
Forman, R. T. T., \& Alexander, L. E. (1998). Roads and their major ecological effects. Annual Review of Ecology and Systematics, 29, 207-231.

Fuller, T. K., \& Sievert, P. R. (2001). Carnivore demography and the consequences of changes in prey availability. In J. L. Gittleman, S. M. Funk, D. W. Macdonald, \& R. K. Wayne (Eds.), Carnivore conservation (pp. 163-178). Cambridge, U.K.: Cambridge University Press and The Zoological Society of London.

Gelman, A., Carlin, J. B., Stern, H. S., \& Rubin, D. B. (2004). Bayesian data analysis. Boca Raton, FL: Chapman and Hall.

Hamel, S., Killengreen, S. T., Henden, J.-A., Eide, N. E., Roed-Eriksen, L., Ims, R. A., \& Yoccoz, N. G. (2013). Towards good practice guidance in using camera-traps in ecology: Influence of sampling design on validity of ecological inferences. Methods in Ecology and Evolution, 4, 105-113.

Hamel, S., Killengreen, S. T., Henden, J.-A., Yoccoz, N. G., \& Ims, R. A. (2013). Disentangling the importance of interspecific competition, food availability, and habitat in species occupancy: Recolonization of the endangered Fennoscandian arctic fox. Biological Conservation, $160,114-120$.

Hampton, S. E., Strasser, C. A., Tewksbury, J. J., Gram, W. K., Budden, A. E., Batcheller, A. L., ... Porter, J. H. (2013). Big data and the future of ecology. Frontiers in Ecology and Environment, 11, 156-162.

Henden, J. A., Stien, A., Bårdsen, B. J., Yoccoz, N. G., \& Ims, R. A. (2014). Community-wide mesocarnivore response to partial ungulate migration. Journal of Applied Ecology, 51, 1525-1533.

Hooper, D. U., Adair, E. C., Cardinale, B. J., Byrnes, J. E. K., Hungate, B. A., Matulich, K. L., ... O'Connor, M. I. (2012). A global synthesis reveals biodiversity loss as a major driver of ecosystem change. Nature, 486, 105-108.

Jones, M. B., Schildhauer, M. P., Reichman, O. J., \& Bowers, S. (2006). The new bioinformatics: Integrating ecological data from the gene to the biosphere. Annual Review of Ecology, Evolution, and Systematics, 37, 519-544.

Kane, M. D., Morin, D. J., \& Kelly, M. J. (2015). Potential for cameratraps and spatial mark-resight models to improve monitoring of the critically endangered West African lion (Panthera leo). Biodiversity and Conservation, 24, 3527-3541.

Karanth, K. L., Nichols, J. D., Samba Kumar, N., Link, W. A., \& Hines, J. E. (2004). Tigers and their prey: Predicting carnivore densities from prey abundance. PNAS, 101, 4854-4858.

Kelling, S., Hochachka, W. M., Fink, D., Riedewald, M., Caruana, R., Ballard, G., \& Hooker, G. (2009). Data-intensive science: A new paradigm for biodiversity studies. BioScience, 59, 613-620.

MacKenzie, D. I., Nichols, J. D., Lachman, G. B., Droege, S., Royle, J. A., \& Langtimm, C. A. (2002). Estimating site occupancy rates when detection probabilities are less than one. Ecology, 83, 2248-2255.

Martins, Q. E. (2010). The ecology of the leopard Panthera pardus in the Cederberg Mountains (Unpublished Doctoral Dissertation). University of Bristol.

Miller, D. A. W., \& Grant, E. H. C. (2015). Estimating occupancy dynamics for large-scale monitoring networks: Amphibian breeding occupancy across protected areas in the northeast United States. Ecology and Evolution, 5, 4735-4746.

O'Brien, T. G., Baillie, J. E. M., Krueger, L., \& Cuke, M. (2010). The Wildlife Picture Index: Monitoring top trophic levels. Animal Conservation, $13,335-343$.

Peters, D. P. C., Groffman, P. M., Nadelhoffer, K. J., Grimm, N. B., Collins, S. L., Michener, W. K., \& Huston, M. A. (2008). Living in an increasingly connected world: A framework for continental-scale environmental science. Frontiers in Ecology and Environment, 6, 229-237. 
Pettorelli, N., Vik, J. O., Mysterud, A., Gaillard, J. M., Tucker, C. J., \& Stenseth, N. C. (2005). Using the satellite-derived NDVI to assess ecological responses to environmental change. Trends in Ecology and Evolution, 20, 503-510.

Plummer, M. (2011). JAGS: A program for the statistical analysis of Bayesian hierarchical models by Markov Chain Monte Carlo. Retrieved from http://sourceforge.net/projects/mcmc-jags/

Rich, L. N., Miller, D. A. W., Robinson, H. S., McNutt, J. W., \& Kelly, M. J. (2016). Using camera trapping and hierarchical occupancy modeling to evaluate the spatial ecology of an African mammal and bird community. Journal of Applied Ecology, 53, 1225-1235.

Ripple, W. J., Estes, J. A., Beschta, R. L., Wilmers, C. C., Ritchie, E. G., Hebblewhite, M., ... Wirsing, A. J. (2014). Status and ecological effects of the world's largest carnivores. Science, 343, 151-163.

Royle, J. A., \& Nichols, J. D. (2003). Estimating abundance from repeated presence-absence data or point counts. Ecology, 84, 777-790.

Schipper, J., Hoffmann, M., Duckworth, J. W., \& Conroy, J. (2008). The 2008 IUCN red listing of the world's small carnivores. Small Carnivore Conservation, 39, 29-34.

Schmeller, D. S., Julliard, R., Bellingham, P. J., Böhm, M., Brummitt, N., Chiarucci, A., ... Belnap, J. (2015). Towards a global terrestrial species monitoring program. Journal for Nature Conservation, 25, 51-57.

Schuette, P., Wagner, A. P., Wagner, M. E., \& Creel, S. (2013). Occupancy patterns and niche partitioning within a diverse carnivore community exposed to anthropogenic pressures. Biological Conservation, 158, 301-312.

Secretariat of the Convention on Biological Diversity (SCBD). (2014). Strategic plan for biodiversity 2011-2020. Retrieved from www.cbd. int/sp/targets

Steenweg, R., Hebblewhite, M., Kays, R., Ahumada, J., Fisher, J. T., Burton, C., ... Rich, L. N. (2017). Scaling-up camera traps: Monitoring the planet's biodiversity with networks of remote sensors. Frontiers in Ecology and Environment, 15, 26-34.

Steenweg, R., Whittington, J., Hebblewhite, M., Forshner, A., Johnston, B., Petersen, D., ... Lukacs, P. (2016). Remote-camera-based occupancy monitoring at large scales: Power to detect trends in grizzly bears across the Canadian Rockies. Biological Conservation, 201, 192-200.

Sunarto, S., Kelly, M. J., Parakkasi, K., \& Hutajulu, M. B. (2015). Cat coexistence in central Sumatra: Ecological characteristics, spatial and temporal overlap, and implications for management. Journal of Zoology, 296, 104-115.
Thapa, K., \& Kelly, M. J. (2017). Density and carrying capacity in the forgotten tigerland: Tigers in understudied Nepalese Churia. Integrative Zoology, 12, 211-227.

Tucker, J. M., Schwartz, M. K., Truex, R. L., Wisely, S. M., \& Allendorf, F. W. (2014). Sampling affects the detection of genetic subdivision and conservation implications for fisher in the Sierra Nevada. Conservation Genetics, 15, 123-136.

Watson, J. E. M., Dudley, N., Segan, D. B., \& Hockings, M. (2014). The performance and potential of protected areas. Nature, 515, 67-73.

Woodroffe, R., \& Ginsberg, J. R. (1998). Edge effects and the extinction of populations inside protected areas. Science, 280, 2126-2128.

Wultsch, C., Waits, L. P., \& Kelly, M. J. (2016). A comparative analysis of genetic diversity and structure in jaguars (Panthera onca), pumas (Puma concolor), and ocelots (Leopardus pardalis) in fragmented landscapes of a critical Mesoamerican linkage zone. PLoS One, 11, e0151043.

Zielinski, W. J., \& Duncan, N. P. (2004). Diets of sympatric populations of American martens (Martes americana) and fishers (Martes pennanti) in California. Journal of Mammalogy, 85, 470-477.

Zipkin, E. F., Royle, J. A., Dawson, D. K., \& Bates, S. (2010). Multi-species occurrence models to evaluate the effects of conservation and management actions. Biological Conservation, 143, 479-484.

\section{BIOSKETCH}

LINDSEY N. RICH's research focuses on population dynamics and community ecology. She uses new, quantitative approaches to assess wildlife data collected using various field techniques (e.g., camera trap surveys, radiotelemetry and public questionnaires) in order to address conservation and management challenges.

\section{SUPPORTING INFORMATION}

Additional Supporting Information may be found online in the supporting information tab for this article.

How to cite this article: Rich LN, Davis CL, Farris ZJ, et al. Assessing global patterns in mammalian carnivore occupancy and richness by integrating local camera trap surveys. Global Ecol Biogeogr. 2017;00:1-12. https://doi.org/10.1111/geb.12600 